\title{
Perceptual Integration Deficits in Autism Spectrum Disorders Are Associated with Reduced Interhemispheric Gamma-Band Coherence
}

\author{
Ina Peiker, ${ }^{1 *}$ Nicole David, ${ }^{1 *}$ ๑Till R. Schneider, ${ }^{1}$ Guido Nolte, ${ }^{1}$ Daniel Schöttle, ${ }^{2}$ and ${ }^{\circledR}$ Andreas K. Engel ${ }^{1}$ \\ Departments of ${ }^{1}$ Neurophysiology and Pathophysiology and ${ }^{2}$ Psychiatry and Psychotherapy, University Medical Center Hamburg-Eppendorf, 20246 \\ Hamburg, Germany
}

\begin{abstract}
The integration of visual details into a holistic percept is essential for object recognition. This integration has been reported as a key deficit in patients with autism spectrum disorders (ASDs). The weak central coherence account posits an altered disposition to integrate features into a coherent whole in ASD. Here, we test the hypothesis that such weak perceptual coherence may be reflected in weak neural coherence across different cortical sites. We recorded magnetoencephalography from 20 adult human participants with ASD and 20 matched controls, who performed a slit-viewing paradigm, in which objects gradually passed behind a vertical or horizontal slit so that only fragments of the object were visible at any given moment. Object recognition thus required perceptual integration over time and, in case of the horizontal slit, also across visual hemifields. ASD participants were selectively impaired in the horizontal slit condition, indicating specific difficulties in long-range synchronization between the hemispheres. Specifically, the ASD group failed to show condition-related enhancement of imaginary coherence between the posterior superior temporal sulci in both hemispheres during horizontal slit-viewing in contrast to controls. Moreover, local synchronization reflected in occipitocerebellar beta-band power was selectively reduced for horizontal compared with vertical slit-viewing in ASD. Furthermore, we found disturbed connectivity between right posterior superior temporal sulcus and left cerebellum. Together, our results suggest that perceptual integration deficits co-occur with specific patterns of abnormal global and local synchronization in ASD.
\end{abstract}

Key words: autism spectrum disorder; coherence; interhemispheric; magnetoencephalography (MEG); oscillation; perceptual integration

\section{Significance Statement}

The weak central coherence account proposes a tendency of individuals with autism spectrum disorders (ASDs) to focus on details at the cost of an integrated coherent whole. Here, we provide evidence, at the behavioral and the neural level, that visual integration in object recognition is impaired in ASD, when details had to be integrated across both visual hemifields. We found enhanced interhemispheric gamma-band coherence in typically developed participants when communication between cortical hemispheres was required by the task. Importantly, participants with ASD failed to show this enhanced coherence between bilateral posterior superior temporal sulci. The findings suggest that visual integration is disturbed at the local and global synchronization scale, which might bear implications for object recognition in ASD.

\section{Introduction}

Integration of visual features is essential for perceiving objects as a coherent whole, a key domain of difficulty in autism spectrum

\footnotetext{
Received April 14, 2015; revised Sept. 23, 2015; accepted 0ct. 25, 2015.

Author contributions: I.P., N.D., T.R.S., and A.K.E. designed research; I.P. and D.S. performed research; I.P. and G.N. analyzed data; I.P., N.D., T.R.S., G.N., D.S., and A.K.E. wrote the paper.

This work was supported by European Union FP7-ICT-270212, ERC-AdG-269716, and H2020-641321 to A.K.E. We thank all volunteers who participated in the experiment; Shigeru Kitazawa for help with the slit-viewing paradigm; Christiane Reissmann and Gerhard Steinmetz for assistance with MEG data recording; and Karin Deazle for help with recruitment and data assessment.

The authors declare no competing financial interests.
}

disorders (ASDs) as proposed by the weak central coherence account (WCC) (Happé and Frith, 2006). It has also been suggested that ASDs represent disorders of information integration or "binding" at the neural level (Brock et al., 2002). Frith (2004) even discussed the possibility of ASD reflecting a disconnection

\footnotetext{
* I.P. and N.D. contributed equally to this work.

Correspondence should be addressed to Dr. Nicole David, Department of Neurophysiology and Pathophysiology, University Medical Center Hamburg-Eppendorf, Martinistrasse 52, 20246 Hamburg, Germany. E-mail: ndavid@uke.de.

DOI:10.1523/JNEUROSCI.1442-15.2015

Copyright $\odot 2015$ the authors $\quad 0270-6474 / 15 / 3516352-10 \$ 15.00 / 0$
} 
syndrome, similar to what has been hypothesized for other disorders, such as schizophrenia. In the typically developed brain, there is increasing evidence that synchronization of oscillatory brain activity in the gamma-frequency band constitutes a mechanism that binds information spatially distributed across the brain (Tallon-Baudry and Bertrand, 1999; Engel and Singer, 2001; Engel et al., 2001). Accordingly, neurons, which represent the same object or event, are active in temporal synchrony (Engel et al., 1991; von der Malsburg, 1994; Engel and Singer, 2001). Indeed, reduced gamma-band activity has been previously associated with perceptual binding deficits in ASD; these studies focused on local synchronization processes and static, illusory stimuli, such as the Kanizsa square and Mooney faces (Sun et al., 2012; e.g., Stroganova et al., 2012). Structural results from diffusion tensor imaging (Travers et al., 2012), as well as functional data from MRI (e.g., Anderson et al., 2011; Dinstein et al., 2011) and M/EEG coherence (e.g., Isler et al., 2010; Khan et al., 2013) also suggest generally compromised anatomical and functional connectivity between distant cortical areas in ASD.

We previously showed that the ability to bind moving dots into a coherent motion percept in an apparent motion stimulus was impaired in ASD, but only when binding across visual hemifields was required (David et al., 2010). Such horizontal binding relies on signal transfer across cortical hemispheres (Chaudhuri and Glaser, 1991; Rose and Büchel, 2005; Helfrich et al., 2014), which led us to assume that a reduction in interhemispheric synchrony might be associated with perceptual integration deficits in ASDs. Here, we recorded magnetoencephalography (MEG) signals from 20 adult participants with ASD and 20 matched controls using an object recognition paradigm that requires the temporal integration of visual details (Parks, 1965). In this paradigm, images of objects pass behind a vertical slit yielding only partial information at any given moment. In a previous study using this stimulus, impaired behavioral performance was shown in ASD (Nakano et al., 2010). We hypothesized that reduced long-range functional connectivity will be associated with perceptual binding difficulties in ASD, especially when coupling between hemispheres is required. To probe long-range integration across cortical hemispheres, we also used a horizontal slit, which spanned both visual hemifields. To quantify the functional connectivity between hemispheres, we calculated interhemispheric imaginary coherence at the cortical source level in ROIs previously implicated in shape and motion perception (Malach et al., 1995; Yin et al., 2002; Beauchamp et al., 2004; Beauchamp, 2005). Although the present study was focused on long-range or global synchronization processes that might be disrupted in ASD, we expected local synchronization as reflected in regional signal power also to be affected.

\section{Materials and Methods}

Participants. Twenty adults with ASD (age $31.2 \pm 8.5$ years; 9 female) and 20 healthy controls (age $31.5 \pm 8.8$ years; 9 female) participated in the study. Six additional participants with ASD were excluded for the following reasons: IQ $<85(n=1)$, drop out $(n=1)$, technical problems $(n=$ $1)$, metal artifacts in MEG recordings $(n=2)$, and behavioral performance $<5 \%(n=1)$. ASD and control participants did not differ significantly with respect to gender, age, IQ, and verbal IQ (Table 1). IQ and Verbal IQ were measured with the Wechsler Adult Intelligence Scale (Wechsler, 1997; Jacobs and Petermann, 2007). To control for potential confounding effects of visual working memory on task performance, we assessed the Figural Memory subtest from the Intelligence Structure Test (Amthauer et al., 2001), which showed no group difference (Table 1). All participants had normal or corrected-to normal vision and were either right- or two-handed. They gave full written informed consent and re-
Table 1. Sample characteristics ${ }^{a}$

\begin{tabular}{lcccc}
\hline & ASD $(n=20)$ & & Control $(n=20)$ & \\
\cline { 2 - 2 } Gender & 9 female & & 9 female & \\
\hline Age & $31.15 \pm 8.46$ & & $31.50 \pm 8.81$ & $0.90, \mathrm{NS}$ \\
IQ & $109.35 \pm 14.38$ & & $110.65 \pm 11.37$ & $0.75, \mathrm{NS}$ \\
Verbal IQ & $111.70 \pm 14.03$ & & $111.25 \pm 13.30$ & $0.92, \mathrm{NS}$ \\
Visual working memory & $107.70 \pm 8.80$ & & $109.8 \pm 10.15$ & $0.49, \mathrm{NS}$ \\
Autism Quotient & $38.05 \pm 8.59$ & & $13.65 \pm 4.65$ & $<0.001$ \\
Depressive symptoms & $7.00,2.00-15.25$ & & $1.00,0-2.00$ & $<0.001$ \\
\hline
\end{tabular}

${ }^{a}$ Depressive symptoms are reported as median and interquartile range, compared in a nonparametric test (Wilco$\mathrm{xon}$ 's rank sum test). All other are reported as mean $\pm S D$, compared in parametric tests (two-sided $t$ test, $\mathrm{df}=38$ ) NS, Not significant.

ceived monetary compensation for their participation. The study was in accordance with the Declaration of Helsinki and approved by the ethics committee of the Hamburg Medical Association.

All participants in the ASD group have been previously been diagnosed meeting the DSM-IV criteria for Autism or Asperger Syndrome (American Psychiatric Association, 2000). Additionally, all diagnoses were confirmed by a local psychiatrist (D.S.), who conducted a semistructured anamnestic interview and the Structured Clinical Interview for DSM-IV axis I and II disorders (Fist et al., 1997, 2002). The Autism Spectrum Quotient (Baron-Cohen et al., 2001) was significantly higher for ASD than for control participants (Table 1). As a common comorbidity of ASD (Ghaziuddin et al., 2002), depressive symptoms were assessed using the Becks Depression Inventory-II (Beck et al., 1996) (Table 1). Among the ASD participants, five participants received antidepressant medication (selective serotonin reuptake inhibitors, tricyclic antidepressants), but they did not show significant differences of task performance compared with ASD participants without antidepressant medication $\left(t_{(22.92)}=0.71 ; p=0.48\right)$. Control participants reported no history of a psychiatric disorder confirmed by the screening modules of the Structured Clinical Interview for DSM-IV axis I and II (Fist et al., 1997, 2002).

Stimuli and task. Stimuli were 244 line-drawings (black lines on white background) from a standardized picture set (Snodgrass and Vanderwart, 1980), depicting objects, animals, and humans. Stimuli extended $3^{\circ}$ on average $\left( \pm 0.8^{\circ} \mathrm{SE}\right)$ and were presented on a back projection screen with an LCD projector (Sanyo Pro Xtrax PLC-XP51) with a refresh rate of $60 \mathrm{~Hz}$ and a spatial resolution of $1024 \times 768$ pixels. The entire display subtended $\sim 30 \times 22^{\circ}$ of visual angle at a viewing distance of $80 \mathrm{~cm}$.

Participants performed an object recognition task. They were instructed to identify images of objects passing behind a narrow slit ("slitviewing") (Parks, 1965). That is, only fragments of the objects were visible at any given moment. For object recognition, these fragments had to be perceptually integrated over time. There were two conditions: Each of the 244 line drawings was presented behind a vertical or horizontal slit (Fig. $1 A)$. At the beginning of each trial, a white slit $\left(0.17^{\circ}\right.$ width $)$ was displayed on a gray background. Participants were asked to fixate a red point centered in the slit, and to maintain fixation throughout the trial. After $1 \mathrm{~s}$, the stimulus appeared moving behind the slit either from left to right (vertical slit) or from top to bottom (horizontal slit). This motion was achieved by shifting the stimulus at each monitor frame one or two pixels to the left (vertical slit condition) or bottom (horizontal slit), resulting in moving speeds of $3.5 \%$ and $7 \%$ and a total stimulus presentation time of 1 s. Notably, Nakano et al. (2010) demonstrated that moving speed does not affect performance in the slit-viewing task. After stimulus presentation, with a delay of $300 \mathrm{~ms}$, participants were cued to verbally report the recognized object (or to indicate if the object was not identified). Each response was recorded on-line and transcribed off-line. Participants pressed a button to continue with the next trial, which started after a blank intertrial interval of 200-600 ms (Fig. 1A). The experimental design comprised variation of two factors: one between factor "group" (ASD vs control), one within factor "slit orientation" (vertical vs horizontal). Conditions were run block-wise in two MEG recording sessions, and the order of the blocks was counterbalanced across participants. In the horizontal slit condition, objects spanned both 

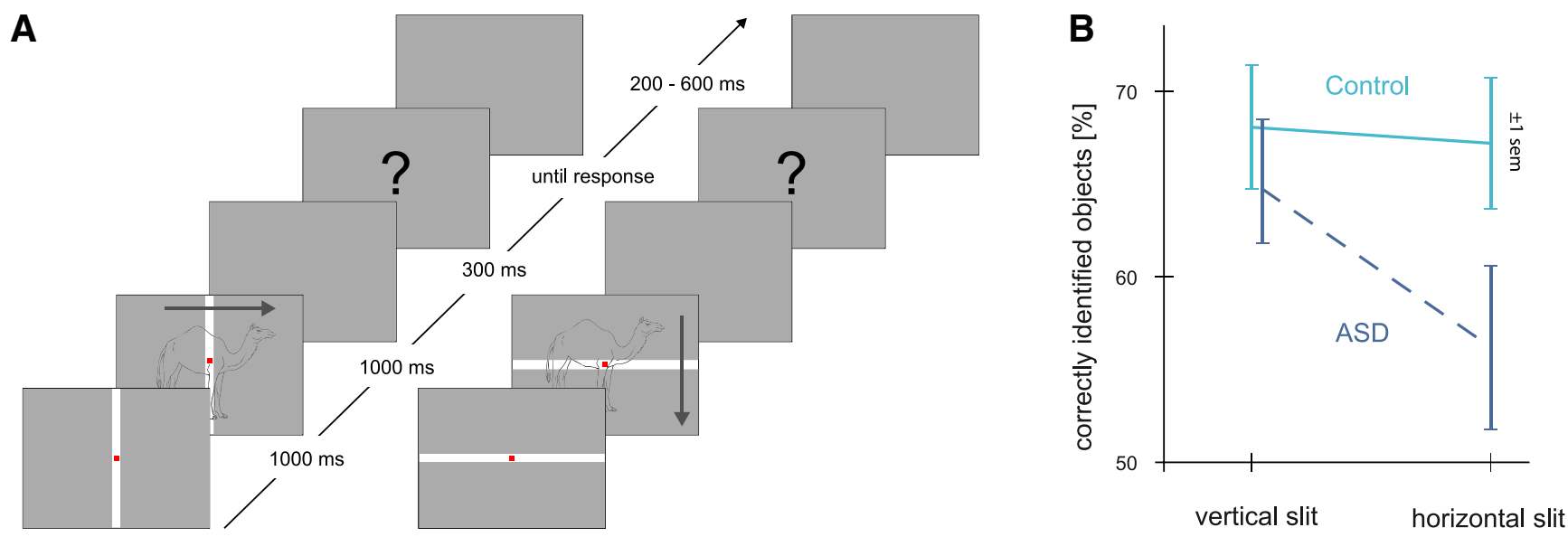

Figure 1. Impaired behavioral performance in ASD during horizontal slit-viewing. $A$, On each trial, participants fixated a central dot while line drawings of objects were moving behind a vertical or horizontal slit. For illustrative purposes, objects are depicted as a whole, whereas in the real experimental procedure they were largely occluded and only visible through the narrow slit. If identified, participants loudly named the perceived object as soon as the "?" occurred on the screen. B, Vertical axis indicates behavioral performance, indexed as the percentage of correctly identified objects. Horizontal axis indicates the two experimental conditions (vertical/horizontal slit). Participants with ASD (broken line) identified less objects during the horizontal compared with the vertical slit condition, whereas conditions did not differ in the control group (solid line) (mean \pm SEM).

visual hemifields. Thus, only in this condition was integration across visual hemifields required.

Behavioral performance indexed by correct trials (in percentage) was compared between groups and conditions in a $2 \times 2$ mixed-model variance analysis with a level of significance at $5 \%$. A trial was defined as correct if at least the stimulus category could be named correctly (e.g.: "animal" for a depicted "dog"). Data were analyzed using R (http://www.r-project.org).

Neurophysiological data acquisition and preprocessing. MEG was recorded continuously using a 275-channel whole-head system (Omega 200 , CTF Systems) in a magnetically shielded room. Four sensors were not operating, resulting in a total of 271 sensors. The electro-occulogram and electrocardiogram were recorded simultaneously for off-line artifact correction. The head position relative to the MEG sensors was measured continuously using a set of head localization coils (nasion, left and right ear). For all analyzed datasets, the head displacement across a recording session was $<20 \mathrm{~mm}$ (mean $\pm \mathrm{SD}: 8.4 \pm 3.7 \mathrm{~mm}$ and $8.3 \pm 3.5 \mathrm{~mm}$ in ASD group and control group). MEG signals were digitized at $1200 \mathrm{~Hz}$ with a low-pass filter at $300 \mathrm{~Hz}$.

The data were bandpass filtered offline $(0.5-250 \mathrm{~Hz}$, low-pass filter at $250 \mathrm{~Hz}$, Butterworth of order 4, forward and backward direction; highpass filter at $0.5 \mathrm{~Hz}$, Butterworth of order 3, forward and backward direction), and line noise was removed using a band-stop filter at 49.5$50.5,99.5-100.5$, and $149.5-150.5 \mathrm{~Hz}$ (Butterworth of order 4, forward and backward direction). The continuous data were epoched from $-1 \mathrm{~s}$ to $1.2 \mathrm{~s}$ time-locked to onset of the moving picture. The mean signal was subtracted. Only correct trials were selected for further analyses. Trials containing signal jumps or strong muscle artifacts were visually detected and rejected from further analysis. Independent component analysis (Hyvärinen, 1999; Jung et al., 2000) was applied, and components containing artifacts related to heartbeats, eye blinks, eye movements, saccadic spike artifacts and remaining muscle activity were rejected from the data. All MEG analyses were performed in MATLAB (The MathWorks) using custom-written scripts and the open source MATLAB toolboxes Fieldtrip (Oostenveld et al., 2010) and SPM2 (http://www.fil.ion.ucl.ac. $\mathrm{uk} / \mathrm{spm})$.

Spectral analysis. Spectral estimates were computed using the multitaper approach based on discrete prolate spheroidal (Slepian) sequences (Mitra and Pesaran, 1999) across equally scaled frequencies $f$ from 2 to $102 \mathrm{~Hz}$ (in $4 \mathrm{~Hz}$ steps) and time $t$ from -500 to $1000 \mathrm{~ms}$ (in $50 \mathrm{~ms}$ steps). A sliding window method was used with fixed taper length $(250 \mathrm{~ms})$ and fixed frequency smoothing $( \pm 8 \mathrm{~Hz}$ ). All transformations to the frequency domain were performed on the single-trial level before averaging across trials. Thus, spectral estimates contained signal components phase-locked and non-phase-locked to the stimulus onset. The resulting total power is reported (Fig. 2) as percentage of change at frequency $f$ relative to the prestimulus baseline (500 ms before up to stimulus onset). Therefore, the average baseline power was first subtracted from the power of the poststimulus interval, and the difference was then divided by the average baseline power.

For analyses at the cortical source level, we computed spectral estimates independently for five separate frequency bands $(4-8 \mathrm{~Hz}$, theta; $8-12 \mathrm{~Hz}$, alpha; $14-36 \mathrm{~Hz}$, beta; $36-60 \mathrm{~Hz}$, low gamma; $60-100 \mathrm{~Hz}$, high gamma) and two time intervals (50-550 $\mathrm{ms}$ and 550-1000 ms after stimulus onset). Although deviating from classical frequency bands, we defined the border between beta- and low gamma-band at $36 \mathrm{~Hz}$ based on our power results because the upper boundary of the beta-band decrease was rather high. Spectral estimates were computed by different approaches for low (theta and $\alpha$ ) and high frequency bands (beta and low/high gamma). In particular, for high frequencies, we used a multitaper approach based on discrete prolate spheroidal (Slepian) sequences (Mitra and Pesaran, 1999), computing spectral estimates on center frequencies with suitable smoothing. For low frequencies (theta and $\alpha$ ), we applied Hanning windows on the two time intervals. Estimated power and cross-spectra were averaged across those frequencies within a frequency band. For instance, time-frequency analysis was performed at 4 and $6 \mathrm{~Hz}$; then, power and cross-spectra were averaged across 4 and $6 \mathrm{~Hz}$ for the analysis of the theta-band. All transformations to the frequency domain were performed on the single-trial level before averaging across trials. Thus, spectral estimates contained signal components phaselocked and non-phase-locked to the stimulus onset. All further power and coherence analyses were performed on the cortical source level.

Source analysis. To estimate the neuronal activity at the cortical source level, we used the "beamforming" adaptive linear spatial filtering technique (Van Veen et al., 1997; Gross et al., 2001). At each source location, three orthogonal filters were computed that pass activity from that location with unit gain while maximally suppressing activity from other sources. We selected different filters depending on the brain parameter of interest (see Coherence analysis and Power analysis). To derive the complex valued source estimates, we multiplied the complex frequency domain data with the real-valued filters.

For all participants, T1-weighted structural MRIs were obtained, which were used to build the individual head models for source analysis. Structural T1-weighted magnetization prepared gradient-echo images $(\mathrm{TR}=2300 \mathrm{~ms}, \mathrm{TE}=2.98 \mathrm{~ms}, \mathrm{FoV}=256 \mathrm{~mm}, 1 \mathrm{~mm}$ slice thickness, $\mathrm{TI}=1100 \mathrm{~ms}, 9^{\circ}$ flip angle) with $1 \times 1 \times 1 \mathrm{~mm}^{3}$ voxel resolution were obtained on a 3T Siemens Magnetom Trio MRI scanner (Siemens Medical Systems) at the University Medical Center Hamburg-Eppendorf. To derive the physical relation between sensors and sources (i.e., the leadfield matrix), individual single-shell head models were constructed from 
ASD
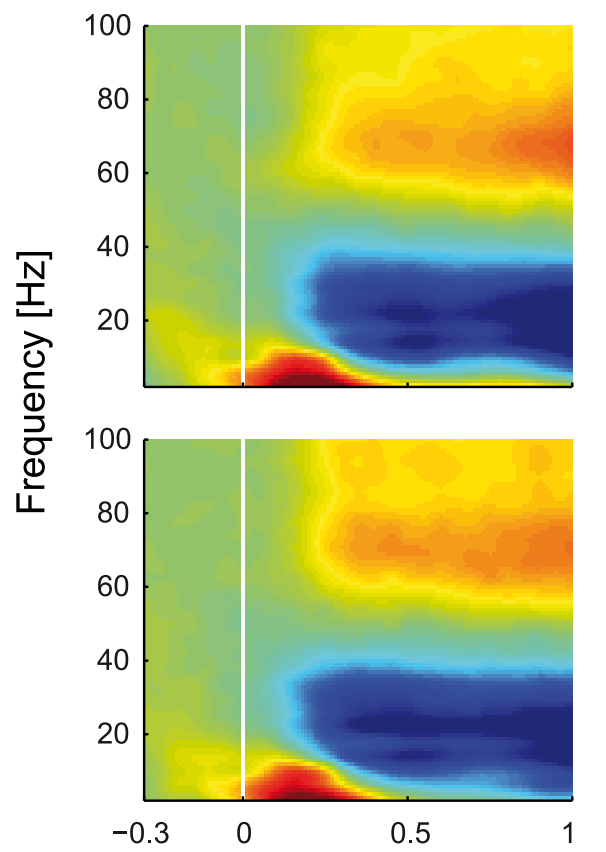

$-0.3$

\section{Response [\%]}

$-20=+20$
Control
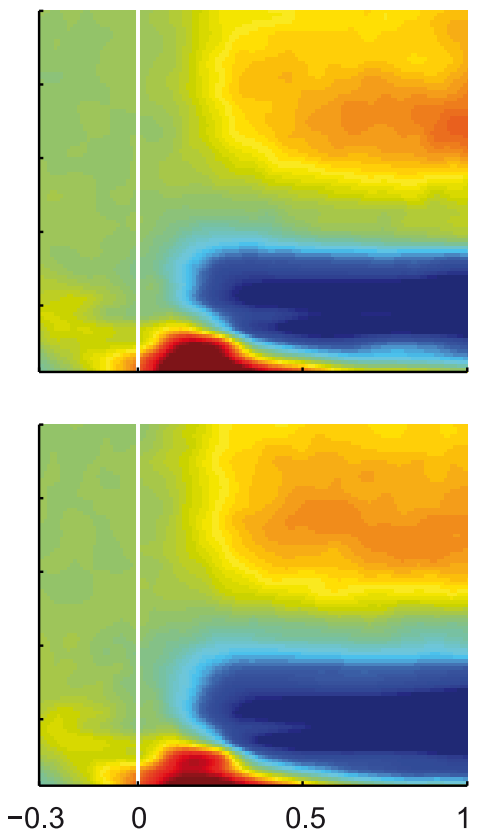

Time $[\mathrm{s}]$

Figure 2. Time-frequency representation of signal power. Signal power was averaged across posterior sensors (highlighted on the schematic head). Stimulus-related power changes are shown for ASD (left column) versus controls (right column) in the vertical slit (top row) and horizontal slit (bottom row) condition. All responses were quantified as the percentage of change in signal amplitude relative to a blank prestimulus baseline interval ( $500 \mathrm{~ms}$ before up to stimulus onset).

the structural MRIs (Nolte, 2003). A regular 3D grid (1 cm spacing) was defined in stereotactic (i.e., MNI) space and transformed into individual head space using the individuals' MRI. MEG sensors were aligned to the individual head geometry based on three fiducial points (nasion, left and right ear).

All source level analyses were independently performed for the aforementioned five frequency bands and two time intervals. We characterized power and coherence responses relative to the prestimulus baseline interval ( -500 to $-50 \mathrm{~ms}$ before stimulus onset). To avoid spurious effects of the filter on the baseline correction, a common filter was used for stimulus and baseline interval.

Coherence analysis. To quantify the frequency-dependent synchronization between pairs of signals, we estimated the imaginary part of coherence at the cortical source level. As a measure of connectivity, we have chosen the maximized imaginary coherence as proposed by Ewald et al. (2012). The idea is that the 3D activity estimated for each voxel by a spatial filter without specifying the source orientation represents mainly activity from neural sources in the vicinity of the voxel, which can have different orientations. In general, it is very well possible that relatively weak sources have a higher connection to a specific region than the strong sources. Choosing a source orientation to maximize power would then miss the interacting sources. It is also very well possible that the different sources with different orientations contributing to the estimate of the activity at a specific voxel interact with different regions. In this case, choosing any fixed source orientation would necessarily miss relevant interaction. To take these effects into account, we optimize the source orientations of two sources for each pair of voxels by maximizing the imaginary part of coherence between the two source activities. We recall here the analytic solution of this optimization problem and refer to Ewald et al. (2012) for the derivation. The input is the 6-dimensional cross-spectrum $C$ ( 2 voxels with 3 orientations each), which we write as follows:

$$
C=\left(\begin{array}{ll}
C_{A A} & C_{A B} \\
C_{A B}^{H} & C_{B B}
\end{array}\right)
$$

where $C_{A A}$ and $C_{B B}$ are the $3 \times 3$ cross-spectra within voxel $\mathrm{A}$ and $\mathrm{B}$, respectively, $C_{A B}$ is the cross-spectrum between the voxels, and the upper index $\mathrm{H}$ denotes hermitian conjugation (i.e., complex conjugation and transpose). We define a matrix $X$ as follows:

$$
X=\left(\operatorname{Re}\left(C_{A A}\right)\right)^{-1 / 2} \operatorname{Im}\left(C_{A B}\right)\left(\operatorname{Re}\left(C_{B B}\right)\right)^{-1 / 2}
$$

Then the maximized imaginary coherence is given by the following:

$$
M I C=\sqrt{\lambda_{\max }}
$$

where $\lambda_{\max }$ is the maximal eigenvalue of $X X^{T}$. As the distribution of imaginary coherence values is non-Gaussian, we applied a nonlinear $z$-transform to the coherence estimates (Nolte et al., 2004). As an additional estimate of coherence, we calculated "lagged coherence" (Pascual-Marqui et al., 2011), also maximized for imaginary coherence.

For baseline correction, activity of the baseline was subtracted from the activity of the stimulus interval. Before statistical testing, imaginary coherence values were averaged across the two time intervals. To provide a calculation of interhemispheric coherence between the left- and right-hemispheric part of the ROIs, we averaged the imaginary coherence between those regions. To quantify differences of interhemispheric coherence between groups and condition, a $2 \times 2$ mixed-model variance analysis was performed. The level of significance was adjusted to $p=0.0033$ to control for multiple comparisons (three ROIs and five frequency bands), using the Bonferroni method (Bonferroni, 1936). To ensure that changes in imaginary coherence reflected changes in phase consistency, rather than changes in signal amplitude, we calculated spectral power averaged between ROIs.

As a post hoc analysis, we calculated imaginary coherence between the posterior superior temporal sulcus (pSTS) and the cerebellum to provide a link between the results of global and local synchronization analyses. Based on previous evidence (Jack et al., 2011; Jack and Morris, 2014; Sokolov et al., 2014; Jack and Pelphrey, 2015), we focused on the right pSTS and the left cerebellum. Baseline correction, averaging of imaginary coherence between regions, and statistical analysis were the same as for interhemispheric coherence analyses.

ROIs. Interhemispheric coherence was calculated at three ROIs, which have previously been associated with motion and shape perception: lateral occipital area (LO) of the lateral occipital complex, human motion area (hMT/V5) and pSTS.

The LO comprises the ventral extent of lateral occipital complex that is implicated in shape perception (Malach et al., 1995; Grill-Spector et al., 1998). LO has been previously defined based on localizer scans (e.g., Grill-Spector et al., 1998) by identifying voxels that showed significantly greater responses to whole versus scrambled objects (Grill-Spector et al., 1998; Lerner et al., 2002; Downing et al., 2007; Eger et al., 2008; Mundy et al., 2012). Here, we used the average of the reported coordinates (MNI coordinates: $-45.4,-75.6,-3.6 ; 44.8,-73.6,-3.0)$ as the center for a spherical ROI of $10 \mathrm{~mm}$ diameter using the WFU PickAtlas software (Lancaster et al., 1997, 2000; Maldjian et al., 2003).

Area hMT/V5, located in the vicinity of the posterior branch of the inferior temporal sulcus, is essentially involved in the perception of mo- 

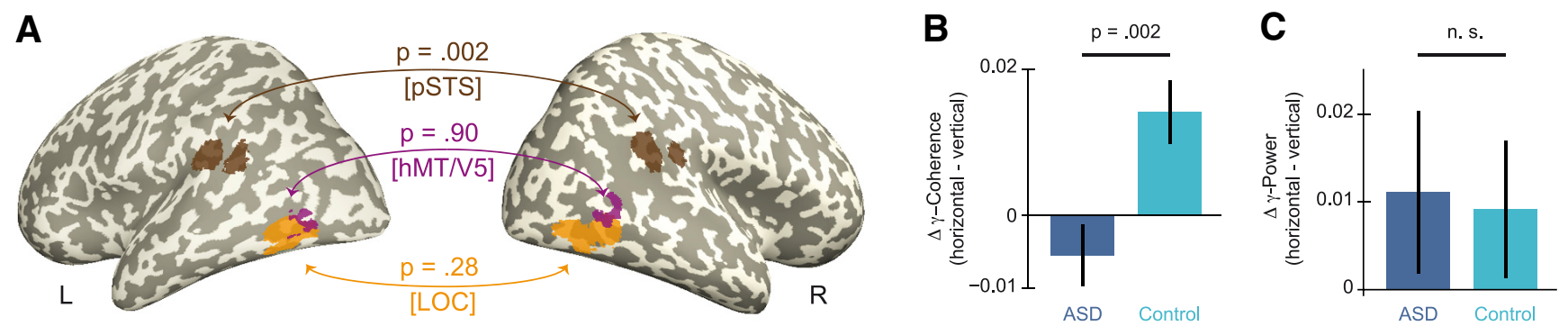

Figure 3. Global synchronization. No enhancement of interhemispheric gamma-band coherence in ASD during horizontal slit-viewing. $A, p$ values, projected on inflated standard MNI cortical surfaces, correspond to the statistical interaction of group $\times$ condition between bilateral L0, hMT/V5, and pSTS. The level of significance was adjusted to $p=0.0033$ to control for multiple comparisons using the Bonferroni method. Low gamma-band $(36-60 \mathrm{~Hz})$ coherence between left and right pSTS reached significance. $\boldsymbol{B}$, In the control group, interhemispheric coherence between bilateral pSTS was enhanced during horizontal slit-viewing, whereas this enhancement was absent in ASD. $C$, The condition-related difference of gamma-band power ( $36-60 \mathrm{~Hz}$ ) did not differ between groups (n.s., not significant), excluding that the coherence effect $(\boldsymbol{A}, \boldsymbol{B})$ was biased by power differences.

tion (Allman and Kaas, 1971; Watson et al., 1993). To define this area as a ROI, we used a probability map provided by the SPM Anatomy Toolbox (Eickhoff et al., 2005; Malikovic et al., 2007).

The pSTS has been associated with the integration of information both within modalities (e.g., visual form, visual motion) and across modalities (Beauchamp et al., 2004; Jellema et al., 2004; Beauchamp, 2005) and with the perception of biological motion (Bonda et al., 1996; Grossman and Blake, 2002). Anatomically defining this area at the posterior part of the superior temporal sulcus (MNI coordinates: $\pm 58,-50,26$ ), we constructed a spherical ROI of $10 \mathrm{~mm}$ diameter using the WFU PickAtlas software (Lancaster et al., 1997, 2000; Maldjian et al., 2003). To calculate imaginary coherence between the pSTS and the cerebellum, the cerebellum has been defined as implemented in the WFU PickAtlas software (Lancaster et al., 1997, 2000; Maldjian et al., 2003).

To evaluate significant cognition-connectivity links more directly, we performed a Pearson-correlation analysis between significant interhemispheric coherence values and behavioral performance (i.e., accuracy on the slit-viewing task). To this end, we calculated the difference between experimental conditions (vertical-horizontal slit-viewing) for each group of participants.

Power analysis. To quantify signal power at the cortical source-level, we selected the filter (i.e., the source orientation) which maximized power. This filter was multiplied with the complex frequency domain data. For baseline correction, activity of the baseline was first subtracted from the activity of stimulus interval; then, the difference was divided by baseline-activity.

Only the interaction of group $\times$ condition was statistically tested. Therefore, a nonparametric permutation test was applied based on spatial clustering (Maris and Oostenveld, 2007). In short, $t$ tests were performed at all cortical locations. Only those data exceeding a criterion $(p<0.05)$ were included in a clustering procedure. Clusters are defined as sets of spatially connected significant data points. On the cluster level, a statistic was calculated by summing up the $t$ values within a cluster. The largest cluster-level statistic was compared with a permutation distribution under the null hypothesis that assignments to groups or conditions are exchangeable. Therefore, data were randomly assigned to groups or conditions and clustered in the same way as the original data. This was done for 3000 repetitions to construct a distribution. Because of the decision on cluster level, only one statistical comparison was performed, and no further correction for multiple comparisons was necessary.

\section{Results}

\section{Behavioral results}

Behavioral performance was measured as the percentage of correctly identified objects per condition. A $2 \times 2$ mixed-measures ANOVA was used to calculate differences between groups (ASD vs control) and conditions (horizontal vs vertical slit). Overall, the two groups did not differ with respect to behavioral performance $\left(F_{(1,38)}=2.04, p=0.16\right)$. There were a significant main effect of condition $\left(F_{(1,38)}=8.20, p=0.01\right)$ and a significant interaction of group and condition $\left(F_{(1,38)}=5.57, p=0.02\right.$; Fig. $1 B)$. Participants with ASD identified fewer objects in the horizontal compared with the vertical slit condition $\left(t_{(19)}=3.82, p=\right.$ 0.001 ), whereas control participants showed no significant performance differences between the vertical and horizontal slit $\left(t_{(19)}=0.35, p=0.73\right)$. These results indicate specific integration difficulties of ASD participants during horizontal slit-viewing.

\section{Coherence results}

As a measure of long-range connectivity between hemispheres, we quantified the imaginary coherence between hemispheres for each of the three ROIs (LO, hMT/V5, pSTS). For pSTS, there was a significant interaction of group $\times$ condition in interhemispheric coherence in the low gamma-frequency band $\left(F_{(1,38)}=\right.$ $10.53, p=0.002$; Fig. 3). Participants of the control group showed stronger interhemispheric coherence in the horizontal compared with the vertical slit condition $\left(t_{(19)}=-3.26, p=0.004\right)$, whereas ASD participants showed no significant difference between the vertical and horizontal slit $\left(t_{(19)}=1.31, p=0.21\right)$. To test the reliability of our method, we repeated the analysis using an additional estimate of coherence ("lagged coherence") (PascualMarqui et al., 2011). This analysis confirmed the previously detected interaction effect between bilateral pSTS in the low gamma-band yielding almost identical results $\left(F_{(1,38)}=10.53\right.$, $p=0.002)$. No main effects were observed in the low gammafrequency band (all $p>0.0033$ ). For the other frequency bands and for LO and hMT/V5, all main or interaction effects were not significant (all $p>0.0033$ ). To ensure that the interaction effect in interhemispheric gamma-band coherence between pSTS reflected true changes in phase consistency rather than changes in signal amplitude, we calculated gamma-band power within pSTS, which showed no significant interaction effect $\left(F_{(1,38)}=\right.$ $0.03, p=0.87$; Fig. $3 B)$. The correlation between interhemispheric coherence of bilateral pSTS and behavioral performance was not significant for either group (ASD: $r=-0.07, p=0.76$; control: $r=0.07, p=0.77)$.

The post hoc analysis of imaginary coherence between right pSTS and left cerebellum yielded a significant group $\times$ condition interaction of in the low gamma-frequency band $\left(F_{(1,38)}=5.39\right.$, $p=0.03$ ). Participants with ASD showed reduced imaginary coherence in the horizontal compared with the vertical slit condition $\left(t_{(19)}=2.42, p=0.03\right)$, whereas participants of the control group showed no significant difference between the vertical and horizontal slit $\left(t_{(19)}=-1.40, p=0.18\right)$. To ensure that the interaction effect in between right pSTS and left cerebellum reflected true changes in phase consistency rather than changes in signal 


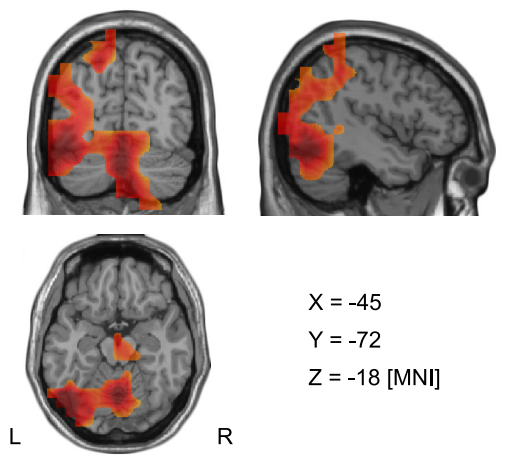

ASD

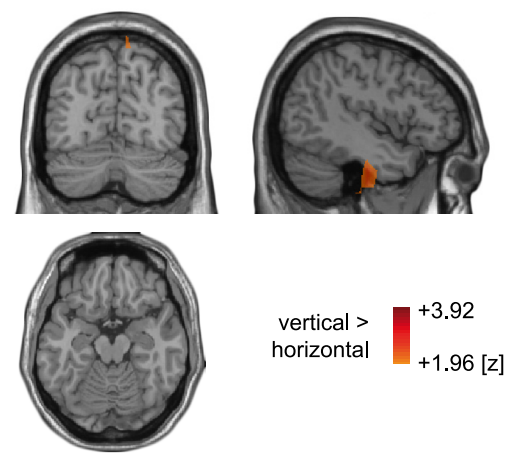

Control

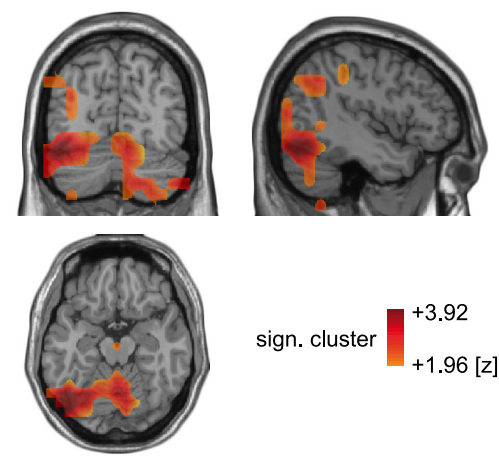

Interaction group by condition

Figure 4. Local synchronization. Reduced beta-band power in ASD during horizontal slit-viewing. Colors represent significant differences of beta-band power (16-36 Hz) between conditions, for ASD (left), control group (middle), and the significant cluster corresponding to the interaction of group $\times$ condition, including inferior parts of occipital cortex and the cerebellum (right). The interaction effect was based on the difference in the ASD group, showing less beta-band power in the horizontal compared with the vertical slit condition, whereas conditions did not differ in the control group. Responses are visualized on sections of the standard MNI brain.

amplitude, we calculated gamma-band power within these regions, which showed no significant interaction effect, either in $\operatorname{pSTS}\left(F_{(1,38)}=0.001, p=0.97\right)$ or in the cerebellum $\left(F_{(1,38)}=\right.$ $0.62, p=0.43)$.

\section{Power results}

Figure 2 depicts the time-frequency representations of neural responses at posterior sensors. After stimulus onset, a transient response from $\sim 50-200 \mathrm{~ms}$ at frequencies $<50 \mathrm{~Hz}$ preceded a tonic response. This tonic response consisted of an increase in signal amplitude in the gamma-frequency range $(>50 \mathrm{~Hz})$ and a decrease at frequencies $\sim<36 \mathrm{~Hz}$.

As a measure of local synchronization in ASD, we analyzed signal power at the cortical source level. To refer to the behavioral and the coherence results, we exclusively calculated the group $\times$ condition interaction term. Permutation tests yielded a significant cluster within the beta-frequency band within the early time window (50-550 ms after stimulus onset) that included visual and cerebellar regions ( $p=0.01$; Fig. 4 ). Beta-band activity was strongly reduced in participants with ASD in the horizontal compared with the vertical slit condition, whereas no difference between conditions was found in the control group. There were no group $\times$ condition effects in the other frequency bands (all $p>$ $0.05)$.

\section{Discussion}

Here, ASD participants showed impaired object recognition when perceptual binding across hemifields and time was required ("horizontal slit-viewing"). This behavioral deficit was matched by neural synchronization abnormalities during horizontal binding in ASD. First, at the global synchronization scale, there was a lack of enhancement of imaginary coherence in the gamma-band between both pSTS. Second, at the local synchronization scale, beta-band power was reduced at inferior temporal/cerebellar cortices. Third, and establishing a link between the two previous results, interhemispheric coherence between pSTS and cerebellum was also reduced in ASD. Our data demonstrate a perceptual integration deficit in ASD at higher levels of information processing in accordance with the WCC account.

\section{Global synchronization}

Control participants showed increased interhemispheric coherence in the gamma-frequency range between bilateral pSTS for perceptual integration across hemifields during horizontal slitviewing. In contrast, participants with ASD failed to show such enhancement in pSTS, which co-occurred with object recognition deficits when horizontal binding was required. ASD has been previously associated with (1) perceptual integration deficits (Plaisted et al., 1999; Milne et al., 2002; Nakano et al., 2010), (2) abnormalities in gamma synchronization (Grice et al., 2001; Brown et al., 2005; Uhlhaas and Singer, 2006; Sokhadze et al., 2009; Stroganova et al., 2012; Sun et al., 2012), (3) structural/ functional abnormalities in the pSTS (Pelphrey et al., 2011), and (4) abnormal brain connectivity between hemispheres (Anderson et al., 2011; Verly et al., 2014; Hahamy et al., 2015). Here, we demonstrate a convergent deficit embracing all four aspects of disturbance.

As our task required the identification of moving objects, we calculated interhemispheric coherence at motion- and shapeselective regions (i.e., LO, hMT/V5, pSTS) (Beauchamp et al., 2004; Beauchamp, 2005). Although LO and hMT/V5 were presumably involved in the slit-viewing task (Yin et al., 2002), our data suggest a coupling deficit in ASD predominantly between left and right pSTS, which possibly relates to the complexity of our stimuli and suggests rather higher-order perceptual integration deficits. The pSTS has been considered as an integrative multimodal brain area (Beauchamp et al., 2004; Beauchamp, 2005), bridging across various functions, such as perceptual integration of visual shape and visual motion (Jellema et al., 2004), biological motion (Grossman and Blake, 2002), and social cognition (Yang et al., 2015). Indeed, people with ASD show deficits related to these functions (Koldewyn et al., 2011; Pelphrey et al., 2011; Scheel et al., 2011; Shih et al., 2011), clearly implicating pSTS as a critical area in disturbed brain networks in ASD.

Our behavioral finding of impaired object recognition during slit-viewing is in line with the WCC account (Happé and Frith, 2006), which has been empirically addressed by numerous studies of perceptual integration in ASD (Plaisted et al., 1999; Milne et al., 2002; Nakano et al., 2010). The pathophysiology underlying WCC has remained a matter of conjecture. The impaired performance during horizontal (i.e., across hemifields) but not vertical binding suggested a specific deficit in long-range interhemispheric connectivity. In accordance, we previously showed (1) specific impairments of apparent motion perception along the horizontal (i.e., also requiring binding across the hemifields) but 
not the vertical meridian in ASD (David et al., 2010; see also O'Keefe and Lindell, 2013), and (2) an association between horizontal apparent motion perception and enhanced gamma-band coupling between motion-selective cortical areas in typically developed participants (Rose and Büchel, 2005; Helfrich et al., 2014). Here, horizontal slit-viewing was also associated with interhemispheric neural coherence in the gamma-band in controls, but not in ASD participants. Abnormalities in the gamma-band have repeatedly been reported for ASD and have been discussed as possible neural signature of WCC (Uhlhaas and Singer, 2006). Brock et al. (2002) suggested that WCC-associated perceptual integration deficits reflect reduced synchronization of gammaband activity between local networks. Our results strongly support this hypothesis (also see evidence on reduced interhemispheric $\mathrm{M} / \mathrm{EEG}$ coherence in frequencies $<13 \mathrm{~Hz}$ ) (Isler et al., 2010; Catarino et al., 2013; Khan et al., 2013; Carson et al., 2014). Yet, in relation to WCC, it has also been suggested that local synchronization within networks is intact or even enhanced (Brock et al., 2002; Belmonte et al., 2004); this could be reflected in higher or no power differences in ASD. The available evidence, including our own, however, does not entirely support this aspect of the hypothesis (Brown et al., 2005; Sokhadze et al., 2009; Baruth et al., 2010; Stroganova et al., 2012; Sun et al., 2012; Buard et al., 2013; Snijders et al., 2013). The kind or degree of perceptual integration required by the visual stimulus or task and the presence or lack of a behavioral deficit might be able to explain empirical inconsistencies. In our study, a local synchronization effect in ASD was found in occipitocerebellar beta-band power, which was reduced for horizontal compared with vertical slitviewing in ASD.

\section{Local synchronization}

Coherence estimates can be confounded by changes in signal-tonoise ratios imposed by fluctuations of local power. To ensure that changes in imaginary coherence reflected changes in phase consistency rather than power, we (1) used a coherence measure that maximizes the imaginary part of coherence, thereby eliminating artifacts from volume conduction (Ewald et al., 2012), and (2) ruled out power differences in the selected ROIs. Our results clearly differentiate global synchronization effects (coherence) from local synchronization effects (power), as they occurred in different frequency bands and at different brain sites.

Participants with ASD showed reduced beta-band power in temporal-cerebellar cortices during horizontal slit-viewing. Oscillatory activity in the beta-band oscillations has been associated with several functions relevant for the slit-viewing task, including sensorimotor predictions (Engel and Fries, 2010), sensory evidence accumulation during decision-making (Donner et al., 2007; Siegel et al., 2011), and visual short-term memory (TallonBaudry et al., 2001). Moreover, there is evidence for disturbed beta-band activity in ASD (Puzzo et al., 2010; Buard et al., 2013; Yoshimura et al., 2013; Leung et al., 2014), for example, during the perception of coherent compared with scrambled shapes (Bangel et al., 2014). The sites of disturbed beta-band activity in our ASD group (i.e., the inferior temporal cortex and the cerebellum) have also previously been implicated in both cognitive processes relevant to our task (e.g., complex object representations in the inferior temporal lobule) (Gauthier and Tarr, 2002; Gerlach et al., 2002) as well as ASD pathology (e.g., Dalton et al., 2005; Wang et al., 2014). Especially the cerebellum has long been implicated in ASD pathophysiology (Courchesne, 1997; Fatemi et al., 2012; Wang et al., 2014). Despite the classical assignment of motor functions to the cerebellum, there is growing evidence for its involvement in perception (Baumann et al., 2015), including the predictive processing of perceptual events (Shadmehr et al., 2010; Popa et al., 2012; Roth et al., 2013).

Given this previous evidence, the ASD-related reduction in cerebellar beta power might reflect impaired sensory prediction and timing in ASD, a deficit that would certainly interfere with our slit-viewing task, which requires the successful integration of visual details over time. This interpretation would be in line with the recent notion of autism as disorder of prediction (Sinha et al., 2014). It is unclear, though, why sensory prediction abnormalities in ASD would affect horizontal more strongly than vertical slit-viewing (see also David et al., 2010). Therefore, it seems more likely that our effect reflects deficits in perceptual motion integration rather than prediction, as the cerebellum has also been related to the perception of biological motion (Bonda et al., 1996; Grossman et al., 2000; Vaina et al., 2001). This interpretation is underlined by previously reported strong functional connectivity between the cerebellum, in particular left Crus 1, and right pSTS (Jack et al., 2011; Sokolov et al., 2012, 2014; Jack and Pelphrey, 2015). Moreover, Jack and Morris (2015) reported disturbed connectivity between these areas in ASD, which predicted mentalizing disabilities in their participants. Our results suggest reduced interhemispheric communication in ASD by means of synchronized activity in the low gamma-frequency range between left cerebellum and right pSTS for perceptual integration across hemifields. This finding nicely links the presently detected ASD-related neural abnormalities at the local and global synchronization level, suggesting that reduced beta-band power is closely related to the lack of enhancement of interhemispheric gamma-band coupling in ASD during perceptual integration.

\section{Limitations}

The lack of correlation between the neuronal dynamics and the behavioral effects limits our conclusions about the functional relationship between interhemispheric gamma-band coherence of bilateral pSTS and impaired perceptual integration across visual hemifields. For the following reasons, we do not think that these two findings are unrelated or merely coincidental: (1) interhemifield perception has been previously associated with interhemispheric signal transfer (e.g., Engel et al., 1991); (2) the pSTS represents a higher-order visual area that has been associated with perceptual-semantic functions closely related to the demands of the slit-viewing task (Beauchamp et al., 2004); (3) our analysis was conservative (e.g., using multiple comparison correction), hypothesis-driven, and focused on specific, taskrelevant ROIs, providing a high level of anatomical specificity; and (4) direct correlations between behavior and neural changes are not easily obtained due to the heterogeneity of behavioral characteristics associated with ASD (Geschwind, 2009) and might require larger sample sizes.

\section{References}

Allman JM, Kaas JH (1971) A representation of the visual field in the caudal third of the middle tempral gyrus of the owl monkey (Aotus trivirgatus). Brain Res 31:85-105. CrossRef Medline

American Psychiatric Association (2000) Diagnostic and statistical manual of mental disorders, Ed 4, text rev. Washington, DC: American Psychiatric Association.

Amthauer R, Brocke B, Liepmann D, Beauducel A (2001) IntelligenzStruktur-Test 2000 R. Göttingen, Germany: Hogrefe.

Anderson JS, Druzgal TJ, Froehlich A, DuBray MB, Lange N, Alexander AL, Abildskov T, Nielsen JA, Cariello AN, Cooperrider JR, Bigler ED, Lainhart JE (2011) Decreased interhemispheric functional connectivity in autism. Cereb Cortex 21:1134-1146. CrossRef Medline

Bangel KA, Batty M, Ye AX, Meaux E, Taylor MJ, Doesburg SM (2014) 
Reduced beta band connectivity during number estimation in autism. Neuroimage Clin 6:202-213. CrossRef Medline

Baron-Cohen S, Wheelwright S, Skinner R, Martin J, Clubley E (2001) The autism-spectrum quotient (AQ): evidence from Asperger syndrome/ high-functioning autism, males and females, scientists and mathematicians. J Autism Dev Disord 31:5-17. CrossRef Medline

Baruth JM, Casanova MF, El-Baz A, Horrell T, Mathai G, Sears L, Sokhadze E (2010) Low-frequency repetitive transcranial magnetic stimulation (rTMS) modulates evoked-gamma frequency oscillations in autism spectrum disorder (ASD). J Neurother 14:179-194. CrossRef Medline

Baumann O, Borra RJ, Bower JM, Cullen KE, Habas C, Ivry RB, Leggio M, Mattingley JB, Molinari M, Moulton EA, Paulin MG, Pavlova MA, Schmahmann JD, Sokolov AA (2015) Consensus paper: the role of the cerebellum in perceptual processes. Cerebellum 14:197-220. CrossRef Medline

Beauchamp MS (2005) See me, hear me, touch me: multisensory integration in lateral occipital-temporal cortex. Curr Opin Neurobiol 15:145153. CrossRef Medline

Beauchamp MS, Lee KE, Argall BD, Martin A (2004) Integration of auditory and visual information about objects in superior temporal sulcus. Neuron 41:809-823. CrossRef Medline

Beck AT, Steer RA, Brown GK (1996) Manual for the Beck Depression Inventory-II. San Antonio: Psychological Corporation.

Belmonte MK, Allen G, Beckel-Mitchener A, Boulanger LM, Carper RA, Webb SJ (2004) Autism and abnormal development of brain connectivity. J Neurosci 24:9228-9231. CrossRef Medline

Bonda E, Petrides M, Ostry D, Evans A (1996) Specific involvement of human parietal systems and the amygdala in the perception of biological motion. J Neurosci 16:3737-3744. Medline

Bonferroni CE (1936) Teoria statistica delle classi e calcolo delle probabilita. Forence, Itlay: Pubblicazioni del R Istituto Superiore di Scienze Economiche e Commerciali di Firenze.

Brock J, Brown CC, Boucher J, Rippon G (2002) The temporal binding deficit hypothesis of autism. Dev Psychopathol 14:209-224. Medline

Brown C, Gruber T, Boucher J, Rippon G, Brock J (2005) Gamma abnormalities during perception of illusory figures in autism. Cortex 41: 364-376. CrossRef Medline

Buard I, Rogers SJ, Hepburn S, Kronberg E, Rojas DC (2013) Altered oscillation patterns and connectivity during picture naming in autism. Front Hum Neurosci 7:742. CrossRef Medline

Carson AM, Salowitz NM, Scheidt RA, Dolan BK, Van Hecke AV (2014) Electroencephalogram coherence in children with and without autism spectrum disorders: decreased interhemispheric connectivity in autism. Autism Res 7:334-343. CrossRef Medline

Catarino A, Andrade A, Churches O, Wagner AP, Baron-Cohen S, Ring H (2013) Task-related functional connectivity in autism spectrum conditions: an EEG study using wavelet transform coherence. Mol Autism 4:1. CrossRef Medline

Chaudhuri A, Glaser DA (1991) Metastable motion anisotropy. Vis Neurosci 7:397-407. CrossRef Medline

Courchesne E (1997) Brainstem, cerebellar and limbic neuroanatomical abnormalities in autism. Curr Opin Neurobiol 7:269-278. CrossRef Medline

Dalton KM, Nacewicz BM, Johnstone T, Schaefer HS, Gernsbacher MA, Goldsmith HH, Alexander AL, Davidson RJ (2005) Gaze fixation and the neural circuitry of face processing in autism. Nat Neurosci 8:519-526. CrossRef Medline

David N, Rose M, Schneider TR, Vogeley K, Engel AK (2010) Brief report: altered horizontal binding of single dots to coherent motion in autism. J Autism Dev Disord 40:1549-1551. CrossRef Medline

Dinstein I, Pierce K, Eyler L, Solso S, Malach R, Behrmann M, Courchesne E (2011) Disrupted neural synchronization in toddlers with autism. Neuron 70:1218-1225. CrossRef Medline

Donner TH, Siegel M, Oostenveld R, Fries P, Bauer M, Engel AK (2007) Population activity in the human dorsal pathway predicts the accuracy of visual motion detection. J Neurophysiol 98:345-359. CrossRef Medline

Downing PE, Wiggett AJ, Peelen MV (2007) Functional magnetic resonance imaging investigation of overlapping lateral occipitotemporal activations using multi-voxel pattern analysis. J Neurosci 27:226-233. CrossRef Medline

Eger E, Ashburner J, Haynes JD, Dolan RJ, Rees G (2008) fMRI activity patterns in human LOC carry information about object exemplars within category. J Cogn Neurosci 20:356-370. CrossRef Medline

Eickhoff SB, Stephan KE, Mohlberg H, Grefkes C, Fink GR, Amunts K, Zilles K (2005) A new SPM toolbox for combining probabilistic cytoarchitectonic maps and functional imaging data. Neuroimage 25:1325-1335. CrossRef Medline

Engel AK, Fries P (2010) Beta-band oscillations: signalling the status quo? Curr Opin Neurobiol 20:156-165. CrossRef Medline

Engel AK, Singer W (2001) Temporal binding and the neural correlates of sensory awareness. Trends Cogn Sci 5:16-25. CrossRef Medline

Engel AK, König P, Kreiter AK, Singer W (1991) Interhemispheric synchronization of oscillatory neuronal responses in cat visual cortex. Science 252:1177-1179. CrossRef Medline

Engel AK, Fries P, Singer W (2001) Dynamic predictions: oscillations and synchrony in top-down processing. Nat Rev Neurosci 2:704-716. CrossRef Medline

Ewald A, Marzetti L, Zappasodi F, Meinecke FC, Nolte G (2012) Estimating true brain connectivity from EEG/MEG data invariant to linear and static transformations in sensor space. Neuroimage 60:476-488. CrossRef Medline

Fatemi SH, Aldinger KA, Ashwood P, Bauman ML, Blaha CD, Blatt GJ, Chauhan A, Chauhan V, Dager SR, Dickson PE, Estes AM, Goldowitz D, Heck DH, Kemper TL, King BH, Martin LA, Millen KJ, Mittleman G, Mosconi MW, Persico AM, et al. (2012) Consensus paper: pathological role of the cerebellum in autism. Cerebellum 11:777-807. CrossRef Medline

Fist M, Gibbon M, Spitzer R, Williams J, Benjamin L (1997) Structured Clinical Interview for DSM-IV Axis II Personality Disorders (SCID-II). Washington, DC: American Psychiatric Association.

Fist M, Spitzer R, Gibbon M, Williams J (2002) Structured Clinical Interview for DSM-IV-TR Axis I Disorders, research version, patient edition. New York: New York State Psychiatric Institute.

Frith C (2004) Is autism a disconnection disorder? Lancet Neurol 3:577. CrossRef Medline

Gauthier I, Tarr MJ (2002) Unraveling mechanisms for expert object recognition: bridging brain activity and behavior. J Exp Psychol Hum Percept Perform 28:431-446. CrossRef Medline

Gerlach C, Aaside CT, Humphreys GW, Gade A, Paulson OB, Law I (2002) Brain activity related to integrative processes in visual object recognition: bottom-up integration and the modulatory influence of stored knowledge. Neuropsychologia 40:1254-1267. CrossRef Medline

Geschwind DH (2009) Advances in autism. Annu Rev Med 60:367-380. CrossRef Medline

Ghaziuddin M, Ghaziuddin N, Greden J (2002) Depression in persons with autism: implications for research and clinical care. J Autism Dev Disord 32:299-306. CrossRef Medline

Grice SJ, Spratling MW, Karmiloff-Smith A, Halit H, Csibra G, de Haan M, Johnson MH (2001) Disordered visual processing and oscillatory brain activity in autism and Williams syndrome. Neuroreport 12:2697-2700. CrossRef Medline

Grill-Spector K, Kushnir T, Hendler T, Edelman S, Itzchak Y, Malach R (1998) A sequence of object-processing stages revealed by fMRI in the human occipital lobe. Hum Brain Mapp 6:316-328. CrossRef Medline

Gross J, Kujala J, Hamalainen M, Timmermann L, Schnitzler A, Salmelin R (2001) Dynamic imaging of coherent sources: studying neural interactions in the human brain. Proc Natl Acad Sci U S A 98:694-699. CrossRef Medline

Grossman ED, Blake R (2002) Brain areas active during visual perception of biological motion. Neuron 35:1167-1175. CrossRef Medline

Grossman E, Donnelly M, Price R, Pickens D, Morgan V, Neighbor G, Blake $\mathrm{R}$ (2000) Brain areas involved in perception of biological motion. J Cogn Neurosci 12:711-720. CrossRef Medline

Hahamy A, Behrmann M, Malach R (2015) The idiosyncratic brain: distortion of spontaneous connectivity patterns in autism spectrum disorder. Nat Neurosci 18:302-309. CrossRef Medline

Happé F, Frith U (2006) The weak coherence account: detail-focused cognitive style in autism spectrum disorders. J Autism Dev Disord 36:5-25. CrossRef Medline

Helfrich RF, Knepper H, Nolte G, Strüber D, Rach S, Herrmann CS, Schneider TR, Engel AK (2014) Selective modulation of interhemispheric functional connectivity by HD-tACS shapes perception. PLoS Biol 12: e1002031. CrossRef Medline

Hyvärinen A (1999) Fast and robust fixed-point algorithms for indepen- 
dent component analysis. IEEE Trans Neural Netw 10:626-634. CrossRef Medline

Isler JR, Martien KM, Grieve PG, Stark RI, Herbert MR (2010) Reduced functional connectivity in visual evoked potentials in children with autism spectrum disorder. Clin Neurophysiol 121:2035-2043. CrossRef Medline

Jack A, Morris JP (2014) Neocerebellar contributions to social perception in adolescents with autism spectrum disorder. Dev Cogn Neurosci 10: 77-92. CrossRef Medline

Jack A, Pelphrey KA (2015) Neural correlates of animacy attribution include neocerebellum in healthy adults. Cereb Cortex 25:4240-4247. CrossRef Medline

Jack A, Englander ZA, Morris JP (2011) Subcortical contributions to effective connectivity in brain networks supporting imitation. Neuropsychologia 49:3689-3698. CrossRef Medline

Jacobs C, Petermann F (2007) Wechsler Intelligenztest für Erwachsene (WIE). Z Für Psychiatr Psychol Psychother 55:205-208.

Jellema T, Maassen G, Perrett DI (2004) Single cell integration of animate form, motion and location in the superior temporal cortex of the macaque monkey. Cereb Cortex 14:781-790. CrossRef Medline

Jung TP, Makeig S, Westerfield M, Townsend J, Courchesne E, Sejnowski TJ (2000) Removal of eye activity artifacts from visual event-related potentials in normal and clinical subjects. Clin Neurophysiol 111:1745-1758. CrossRef Medline

Khan S, Gramfort A, Shetty NR, Kitzbichler MG, Ganesan S, Moran JM, Lee SM, Gabrieli JD, Tager-Flusberg HB, Joseph RM, Herbert MR, Hämäläinen MS, Kenet T (2013) Local and long-range functional connectivity is reduced in concert in autism spectrum disorders. Proc Natl Acad Sci U S A 110:3107-3112. CrossRef Medline

Koldewyn K, Whitney D, Rivera SM (2011) Neural correlates of coherent and biological motion perception in autism. Dev Sci 14:1075-1088. CrossRef Medline

Lancaster JL, Summerln JL, Rainey L, Freitas CS, Fox PT (1997) The Talairach Daemon, a database server for Talairach atlas labels. Neuroimage 5:S633.

Lancaster JL, Woldorff MG, Parsons LM, Liotti M, Freitas CS, Rainey L, Kochunov PV, Nickerson D, Mikiten SA, Fox PT (2000) Automated Talairach atlas labels for functional brain mapping. Hum Brain Mapp 10:120-131. CrossRef Medline

Lerner Y, Hendler T, Malach R (2002) Object-completion effects in the human lateral occipital complex. Cereb Cortex 12:163-177. CrossRef Medline

Leung RC, Ye AX, Wong SM, Taylor MJ, Doesburg SM (2014) Reduced beta connectivity during emotional face processing in adolescents with autism. Mol Autism 5:51. CrossRef Medline

Malach R, Reppas JB, Benson RR, Kwong KK, Jiang H, Kennedy WA, Ledden PJ, Brady TJ, Rosen BR, Tootell RB (1995) Object-related activity revealed by functional magnetic resonance imaging in human occipital cortex. Proc Natl Acad Sci U S A 92:8135-8139. CrossRef Medline

Maldjian JA, Laurienti PJ, Kraft RA, Burdette JH (2003) An automated method for neuroanatomic and cytoarchitectonic atlas-based interrogation of fMRI data sets. Neuroimage 19:1233-1239. CrossRef Medline

Malikovic A, Amunts K, Schleicher A, Mohlberg H, Eickhoff SB, Wilms M, Palomero-Gallagher N, Armstrong E, Zilles K (2007) Cytoarchitectonic analysis of the human extrastriate cortex in the region of V5/MT+: a probabilistic, stereotaxic map of area hOc5. Cereb Cortex 17:562-574. CrossRef Medline

Maris E, Oostenveld R (2007) Nonparametric statistical testing of EEG- and MEG-data. J Neurosci Methods 164:177-190. CrossRef Medline

Milne E, Swettenham J, Hansen P, Campbell R, Jeffries H, Plaisted K (2002) High motion coherence thresholds in children with autism. J Child Psychol Psychiatry 43:255-263. CrossRef Medline

Mitra PP, Pesaran B (1999) Analysis of dynamic brain imaging data. Biophys J 76:691-708. CrossRef Medline

Mundy ME, Downing PE, Graham KS (2012) Extrastriate cortex and medial temporal lobe regions respond differentially to visual feature overlap within preferred stimulus category. Neuropsychologia 50:3053-3061. CrossRef Medline

Nakano T, Ota H, Kato N, Kitazawa S (2010) Deficit in visual temporal integration in autism spectrum disorders. Proc Biol Sci 277:1027-1030. CrossRef Medline

Nolte G (2003) The magnetic lead field theorem in the quasi-static approx- imation and its use for magnetoencephalography forward calculation in realistic volume conductors. Phys Med Biol 48:3637-3652. CrossRef Medline

Nolte G, Bai O, Wheaton L, Mari Z, Vorbach S, Hallett M (2004) Identifying true brain interaction from EEG data using the imaginary part of coherency. Clin Neurophysiol 115:2292-2307. CrossRef Medline

O'Keefe N, Lindell AK (2013) Reduced interhemispheric interaction in non-autistic individuals with normal but high levels of autism traits. Brain Cogn 83:183-189. CrossRef Medline

Oostenveld R, Fries P, Maris E, Schoffelen JM (2010) FieldTrip: open source software for advanced analysis of MEG, EEG, and invasive electrophysiological data. Comput Intell Neurosci 2011:e156869. CrossRef Medline

Parks TE (1965) Post-retinal visual storage. Am J Psychol 78:145-147. CrossRef Medline

Pascual-Marqui RD, Lehmann D, Koukkou M, Kochi K, Anderer P, Saletu B, Tanaka H, Hirata K, John ER, Prichep L, Biscay-Lirio R, Kinoshita T (2011) Assessing interactions in the brain with exact low-resolution electromagnetic tomography. Philos Trans A Math Phys Eng Sci 369: 3768-3784. CrossRef Medline

Pelphrey KA, Shultz S, Hudac CM, Vander Wyk BC (2011) Research review: constraining heterogeneity: the social brain and its development in autism spectrum disorder. J Child Psychol Psychiatry 52:631-644. CrossRef Medline

Plaisted K, Swettenham J, Rees L (1999) Children with autism show local precedence in a divided attention task and global precedence in a selective attention task. J Child Psychol Psychiatry 40:733-742. CrossRef Medline

Popa LS, Hewitt AL, Ebner TJ (2012) Predictive and feedback performance errors are signaled in the simple spike discharge of individual Purkinje cells. J Neurosci 32:15345-15358. CrossRef Medline

Puzzo I, Cooper NR, Vetter P, Russo R (2010) EEG activation differences in the pre-motor cortex and supplementary motor area between normal individuals with high and low traits of autism. Brain Res 1342:104-110. CrossRef Medline

Rose M, Büchel C (2005) Neural coupling binds visual tokens to moving stimuli. J Neurosci 25:10101-10104. CrossRef Medline

Roth MJ, Synofzik M, Lindner A (2013) The cerebellum optimizes perceptual predictions about external sensory events. Curr Biol 23:930-935. CrossRef Medline

Scheel C, Rotarska-Jagiela A, Schilbach L, Lehnhardt FG, Krug B, Vogeley K, Tepest R (2011) Imaging derived cortical thickness reduction in highfunctioning autism: key regions and temporal slope. Neuroimage 58: 391-400. CrossRef Medline

Shadmehr R, Smith MA, Krakauer JW (2010) Error correction, sensory prediction, and adaptation in motor control. Annu Rev Neurosci 33:89-108. CrossRef Medline

Shih P, Keehn B, Oram JK, Leyden KM, Keown CL, Müller RA (2011) Functional differentiation of posterior superior temporal sulcus in autism: a functional connectivity magnetic resonance imaging study. Biol Psychiatry 70:270-277. CrossRef Medline

Siegel M, Engel AK, Donner TH (2011) Cortical network dynamics of perceptual decision-making in the human brain. Front Hum Neurosci 5:21. CrossRef Medline

Sinha P, Kjelgaard MM, Gandhi TK, Tsourides K, Cardinaux AL, Pantazis D, Diamond SP, Held RM (2014) Autism as a disorder of prediction. Proc Natl Acad Sci U S A 111:15220-15225. CrossRef Medline

Snijders TM, Milivojevic B, Kemner C (2013) Atypical excitation-inhibition balance in autism captured by the gamma response to contextual modulation. Neuroimage Clin 3:65-72. CrossRef Medline

Snodgrass JG, Vanderwart M (1980) A standardized set of 260 pictures: norms for name agreement, image agreement, familiarity, and visual complexity. J Exp Psychol Hum Learn 6:174-215. CrossRef Medline

Sokhadze EM, El-Baz A, Baruth J, Mathai G, Sears L, Casanova MF (2009) Effects of low frequency repetitive transcranial magnetic stimulation (rTMS) on gamma frequency oscillations and event-related potentials during processing of illusory figures in autism. J Autism Dev Disord 39: 619-634. CrossRef Medline

Sokolov AA, Erb M, Gharabaghi A, Grodd W, Tatagiba MS, Pavlova MA (2012) Biological motion processing: the left cerebellum communicates with the right superior temporal sulcus. Neuroimage 59:2824-2830. CrossRef Medline

Sokolov AA, Erb M, Grodd W, Pavlova MA (2014) Structural loop between 
the cerebellum and the superior temporal sulcus: evidence from diffusion tensor imaging. Cereb Cortex 24:626-632. CrossRef Medline

Stroganova TA, Orekhova EV, Prokofyev AO, Tsetlin MM, Gratchev VV, Morozov AA, Obukhov YV (2012) High-frequency oscillatory response to illusory contour in typically developing boys and boys with autism spectrum disorders. Cortex 48:701-717. CrossRef Medline

Sun L, Grützner C, Bölte S, Wibral M, Tozman T, Schlitt S, Poustka F, Singer W, Freitag CM, Uhlhaas PJ (2012) Impaired gamma-band activity during perceptual organization in adults with autism spectrum disorders: evidence for dysfunctional network activity in frontal-posterior cortices. J Neurosci 32:9563-9573. CrossRef Medline

Tallon-Baudry C, Bertrand O (1999) Oscillatory gamma activity in humans and its role in object representation. Trends Cogn Sci 3:151-162. CrossRef Medline

Tallon-Baudry C, Bertrand O, Fischer C (2001) Oscillatory synchrony between human extrastriate areas during visual short-term memory maintenance. J Neurosci 21:RC177. Medline

Travers BG, Adluru N, Ennis C, Tromp do PM, Destiche D, Doran S, Bigler ED, Lange N, Lainhart JE, Alexander AL (2012) Diffusion tensor imaging in autism spectrum disorder: a review. Autism Res 5:289-313. CrossRef Medline

Uhlhaas PJ, Singer W (2006) Neural synchrony in brain disorders: relevance for cognitive dysfunctions and pathophysiology. Neuron 52:155-168. CrossRef Medline

Vaina LM, Solomon J, Chowdhury S, Sinha P, Belliveau JW (2001) Functional neuroanatomy of biological motion perception in humans. Proc Natl Acad Sci U S A 98:11656-11661. CrossRef Medline

Van Veen BD, van Drongelen W, Yuchtman M, Suzuki A (1997) Localiza- tion of brain electrical activity via linearly constrained minimum variance spatial filtering. IEEE Trans Biomed Eng 44:867-880. CrossRef Medline

Verly M, Verhoeven J, Zink I, Mantini D, Peeters R, Deprez S, Emsell L, Boets B, Noens I, Steyaert J, Lagae L, De Cock P, Rommel N, Sunaert S (2014) Altered functional connectivity of the language network in ASD: role of classical language areas and cerebellum. Neuroimage Clin 4:374-382. CrossRef Medline

von der Malsburg C (1994) The correlation theory of brain function. In: Models of neural networks (Domany PE, van Hemmen PDJL, Schulten PK, eds), pp 95-119. New York: Springer.

Wang SS, Kloth AD, Badura A (2014) The cerebellum, sensitive periods, and autism. Neuron 83:518-532. CrossRef Medline

Watson JD, Myers R, Frackowiak RS, Hajnal JV, Woods RP, Mazziotta JC, Shipp S, Zeki S (1993) Area V5 of the human brain: evidence from a combined study using positron emission tomography and magnetic resonance imaging. Cereb Cortex 3:79-94. CrossRef Medline

Wechsler D (1997) WAIS-III: Wechsler Adult Intelligence Scale. San Antonio: Psychological Corporation.

Yang DY, Rosenblau G, Keifer C, Pelphrey KA (2015) An integrative neural model of social perception, action observation, and theory of mind. Neurosci Biobehav Rev 51:263-275. CrossRef Medline

Yin C, Shimojo S, Moore C, Engel SA (2002) Dynamic shape integration in extrastriate cortex. Curr Biol 12:1379-1385. CrossRef Medline

Yoshimura Y, Kikuchi M, Ueno S, Okumura E, Hiraishi H, Hasegawa C, Remijn GB, Shitamichi K, Munesue T, Tsubokawa T, Higashida H, Minabe Y (2013) The brain's response to the human voice depends on the incidence of autistic traits in the general population. PLoS One 8:e80126. CrossRef Medline 